\title{
Penerapan Teknologi Mesin Bending Guna Mempercepat Proses Bending pada Produk Gantungan Ayam di PT Todda Perkasa Semarang
}

\author{
Ampala Khoryanton*, Adhy Purnomo, Farika Tono Putri, Miftah Nashrullah \\ Teknik Mesin, Politeknik Negeri Semarang, \\ Jl. Prof. Sudarto, SH , Semarang, 50275 \\ *E-mail: ampala.khoryanton@polines.ac.id
}

Diterima: 04-11-2021; Direvisi: 21-11-2021; Dipublikasi: 30-12-2021

\begin{abstract}
Abstrak
PT Todda Perkasa Semarang merupakan ukm yang berkecimpung dalam industri produksi peralatan dapur, alat pengolah makanan dan rumah potong ayam. Material yang digunakan adalah stainless steel untuk membuat produkproduknya. Saat ini produk hanger/gantungan ayam merupakan produk unggulan di perusahaan ini karena order dari customer (rumah potong ayam) sangat besar mencapai 300 unit per minggu, namun tidak semua order bisa di tangani dengan baik. Perusahaan masih mengalami hambatan dibidang teknologi dan manajemen produksinya. Hanger/gantungan ayam tersebut diproduksi dengan gerinda tangan untuk memotong raw material kemudian dilakukan penekukan dengan mesin bending manual, akibat mesin bending yang masih manual dan mengandalkan tenaga operator sehingga produktivitas produksi hanger/gantungan ayam rendah sehingga perusahaan membatasi penerimaan pesanan produk tersebut. Penelitian tentang mesin bending sudah ada diantaranya perancangan mesin bending untuk menurunkan reject mechanical packing kapasitor, peningkatan produktivitas art x pada mesin bending LR, perancangan sistem kontrol PLC pada mesin bending rol pipa, rancang bangun mesin roll bending portable, namun mesin bending model rotary yang di aplikasikan pada hanger ayam potong belum pernah dilakukan dalam penelitian. Tujuan dari penelitian ini adalah melakukan redesain mesin bending model rotary dengan penggerak motor listrik, dan melakukan pendampingan teknologi pengoperasian pada karyawan PT. Todda Perkasa. Metode yang digunakan dalam penelitian ini adalah melakukan redesign pada mesin tekuk proses pembuatan dan pengujian alat. Hasil penelitian ini menujukkan hasil redesign sudah sesuai kualitas yang diharapkan serta waktu proses bending dapat dipercepat 656,7 detik
\end{abstract}

Kata kunci: Hanger Ayam; Mesin Bending Rotary; Waktu Proses Bending.

\begin{abstract}
PT Todda Perkasa Semarang is a SME that is engaged in the production of kitchen equipment, food processing equipment and chicken slaughterhouses. The material used is stainless steel to make its products. Currently the chicken hanger product is a superior product in this company because orders from customers (chicken slaughterhouses) are very large, reaching 300 units per week, but not all orders can be handled properly. The company is still experiencing obstacles in the field of technology and production management. The hanger/chicken hanger is produced by hand grinding to cut the raw material and then bending it with a manual bending machine, due to the bending machine that is still manual and relies on operator power so that the productivity of the hanger/chicken hanger production is low so that the company limits the acceptance of orders for these products. Research on bending machines already exists including the design of bending machines to reduce reject mechanical packing capacitors, increasing productivity of art $x$ on LR bending machines, designing PLC control systems on pipe roller bending machines, designing portable roll bending machines, but the rotary model bending machine used application to chicken hangers has never been done in a study. The purpose of this research is to redesign a rotary bending machine with an electric motor drive, and to provide technical assistance to employees of PT Todda Perkasa Semarang. The method used in this research is to redesign the bending machine for the manufacturing process and testing the tool. The results of this study show that the redesign results are in accordance with the expected quality and the bending process time can be accelerated by 656.7 seconds
\end{abstract}

Keywords: Chicken Hangers; Bending Process Time; Rotary Bending Machine.

\section{Pendahuluan}

PT. Todda Perkasa, Kedungmundu, Semarang adalah perusahaan yang memproduksi peralatan untuk rumah potong ayam seperti hanger atau gantungan ayam, rail, kitchen set, dan lain-lain. Perusahaan ini hanya mengerjakan produk- 
produknya apabila ada permintaan dari customer. Karena keterbatasan karyawan dan alat bantu yang dimiliki masih manual, maka perusahaan ini membatasi setiap ada permintaan dari customer.

Proses pembuatan hanger atau gantungan ayam potong dapat dilihat Gambar 1 pada PT. Todda Perkasa dimulai dari proses pemotongan (cutting) bahan baku stainles steel berdiameter $6 \mathrm{~mm}$ dengan menggunakan mesin gerinda tangan, selanjutnya dilakukan proses bending menggunakan alat bending manual. Proses terakhir adalah merakit komponenkomponen hanger ayam mengunakan metode pengelasan.

Permasalahan yang dihadapi PT. Todda Perkasa adalah produksi hanger atau gantungan ayam masih sangat terbatas, yaitu hanya dapat membuat 6 pes per harinya padahal order dari customer rumah potong ayam per minggunya mencapai 300 unit. Ditinjau dari segi ekonomi hal ini merupakan kerugian bagi PT. Todda Perkasa karena kehilangan kesempatan memperoleh profit yang lebih besar.

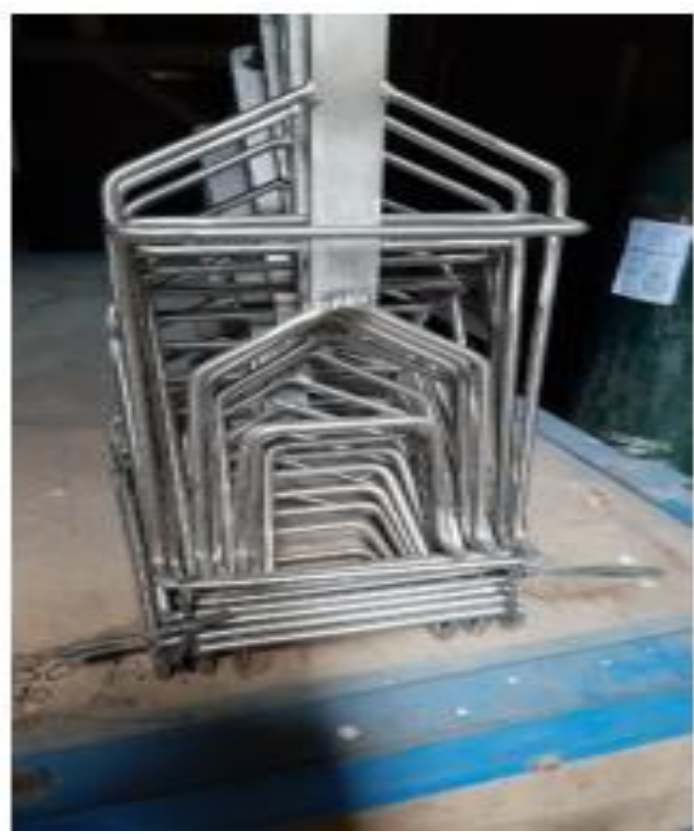

Gambar 1. Hanger atau gantingan ayam Potong

Berdasarkan hasil wawancara di lapangan, PT. Todda Perkasa membatasi kapasitas produksi 6 pcs perharinya karena keterbatasan fasilitas produksi dan penguasaan teknologi sdm nya masih belum optimal. Hasil pengamatan di lapangan untuk melakukan proses bending ini digunakan Mesin bending konvensional Gambar 2 dan menunjukkan bahwa sering terjadi line stop pada proses penekukan/bending round bar stainless steel diameter $6 \mathrm{~mm}$ setelah dilakukan proses cutting. Waktu yang butuhkan untuk melakukan proses bending sekitar 5 menit per unit hanger gantungan ayam (terdapat 5 komponen round bar yang harus dibending). Sementara kualitas hasil bending banyak yang tidak sesuai sudutnya sehingga harus dilakukan proses repair dan membutuhkan waktu rata 10 menit untuk 1 set hanger.

Rumusan permasalahannya adalah bagaimana mempercepat proses bending agar produktivitas hanger gantungan ayam bisa dinaikkan sehingga profit perusahaan akan lebih besar? Mesin bending dapat menghemat waktu kerja serta dapat menghasilkan hasil yang lebih presisi dengan proses yang mudah, praktis, cepat serta memberikan hasil yang lebih baik dari sebelumnya [1]. Proses penekukan logam besi maupun non besi dinamakan dengan bending. Proses pemuluran dan peregangan terjadi pada daerah bidang netral sepanjang garis bending sehingga menghasilkan garis bending lurus [2]. 
Ampala Khoryanton dkk /Jurnal Rekayasa Mesin

p-ISSN: 1411-6863, e-ISSN: 2540-7678

Vol.16|No.3|417-424|Desember|2021

Penelitian lain terkait tentang rancang dan bangun mesin roll bending sudah banyak dilakukan pada penelitian sebelumya. Perancangan Mesin Bending untuk Menurunkan Reject Mechanical Packing Kapasitor[3], Peningkatan Produktivitas Part X Pada Mesin Bending LR [4], Perancangan Sistem Kontrol PLC Pada Mesin Bending Rol Pipa [5], Rancang Bangun Mesin Roll Bending Portable [6]. Ashok Marcharla dkk. (2017) dalam penelitiannya yang berjudul "Design and Analysis of Rotary Draw Tube Bending Machine" membahas mengenai contoh design pada mesin bending dan analisis gaya momen, gaya gesek statis pada design yang digunakan[3]. Christopher dkk. (2018) dalam penelitiannya yang berjudul "Rotary Draw Bending Using Tools with Reduced Geometries" membahas mengenai pengaruh variasi permukaan pada die clamp terhadap hasil penekukan besi poros [4]. Syafrizal dkk. (2017) dalam penelitiannya yang berjudul "Pemilihan Daya Motor Sebagai Sumber Penggerak Dengan Menggunakan Transmisi Pulley dan V-Belt" membahas mengenai pemilihan daya motor listrik sebagai sumber penggerak dengan efektif sesuai dengan kebutuhan yang diinginkan [5]. Zufar, S., R. (2017) dalam penelitiannya yang berjudul "Analisis Springback Tube Stainless Steel 304L Berpenampang Lingkaran dan Elips Pada Proses Rotary Draw Bending" membahas mengenai analisa yang terjadi apabila menggunakan variasi diameter tube dan sudut bending terhadap springback [6]. Penelitian berikutnya adalah mesin roll pipa hidrolis yang digunakan pada bengkel modifikasi konstruksi motor trail[7], dimana keunggulan dari mesin tersebut memiliki rentang aplikasi diameter pipa yang lebih besar, dengan tingkat keamanan dan kenyamanan yang lebih baik.

Tujuan dari penelitian ini adalah melakukan redesign mesin bending model rotary dengan penggerak motor listrik. Diharapkan dengan penelitian ini dapat menaikkan produktifitas hanger atau gantungan ayam potong.

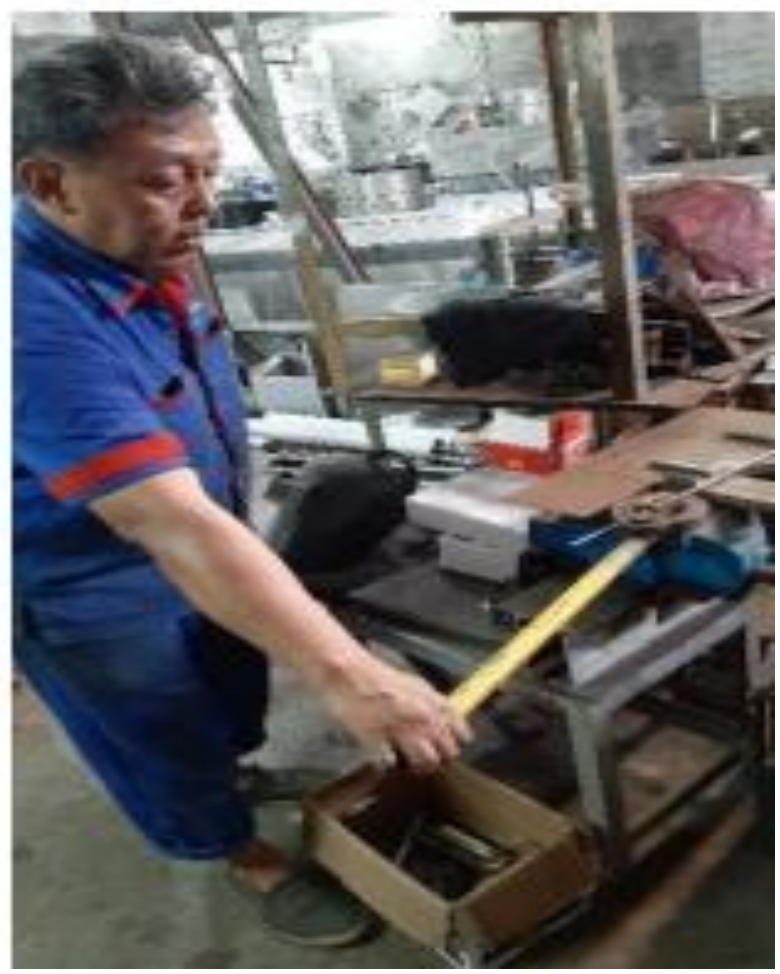

Gambar 2. Proses Bending Konvensional di PT. Todda Perkasa

\section{Metodologi}

Metode yang digunakan dalam penelitian ini adalah melakukan redesign pada mesin tekuk proses pembuatan dan pengujian alat. Seperti terlihat pada Gambar 3 flow chart metode penelitian. Dimulai dengan melakukan Redesign Mesin bending dengan penggerak motor listrik dirancang menggunakan Software Solid works, proses pembuatan 
komponen dan perakitan, selanjutnya dilakukan pengujian fungsi mesin bending rotary apabila dari segi fungsi masih terdapat kekurangan maka akan kembali di lakukan perancangan ulang dan modifikasi beberapa part nya. Selanjutnya apabila uji fungsi sudah tercapai akan dilanjutkan analisis hasil proses bending. Agar dapat diterapkan di PT. Todda Perkasa maka dilaksankan pelatihan operasional kepada karyawannya.

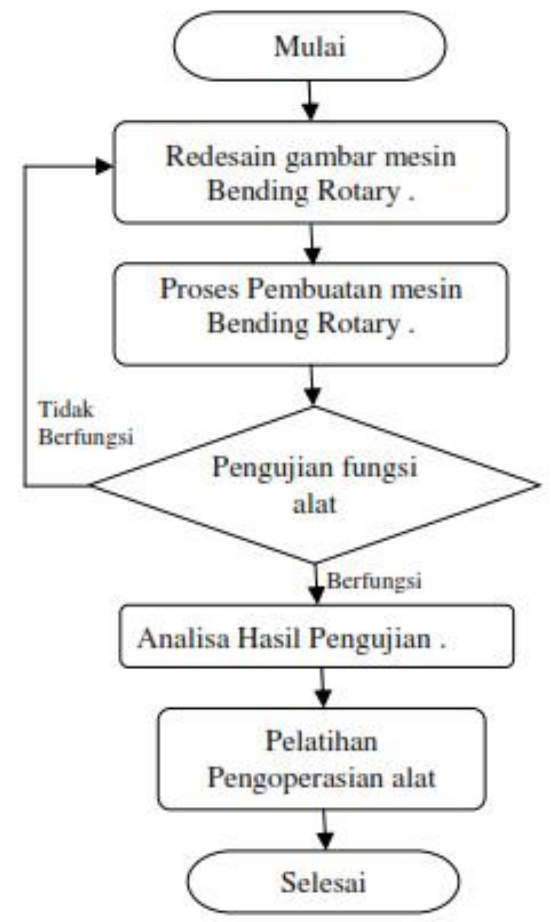

Gambar 3. Flow Chart Metode Penelitian

\section{Hasil dan Pembahasan}

\subsection{Redesign Mesin Bending Rotary}

Proses pembengkokan atau bending besi poros atau round bar harus dilakukan dengan cara yang tepat dan tentunya dengan menggunakan alat atau mesin yang tepat [8]. Perubahan bentuk dari bahan tersebut akan di bantu dengan alat yang sering disebut tools. Tools tersebut akan memberikan gaya tekan guna untuk memberi bentuk pada bahan besi poros atau round bar logam tersebut dengan sesuai geometri dan bentuk tools tersebut [9]. Redesign Mesin bending penggerak motor listrik dirancang menggunakan Software Solid works. Hasil perencanaan mesin dapat ditunjukkan pada Gambar 4 mempunyai dimensi $600 \mathrm{~mm}$ x $600 \mathrm{~mm}$ x $1200 \mathrm{~mm}$, menggunakan motor listrik 1/2 HP sebagai sumber tenaga mesin.

Untuk sistem transmisi menggunakan 1 pulley dan 1 transmission gear. Bagian body mesin menggunakan besi hollow dengan dimensi $40 \mathrm{~mm}$ x $40 \mathrm{~mm}$ x $2 \mathrm{~mm}$. Pada pembuatan roller menggunakan AISI 1045 dengan diameter 20 mm serta menyatu dengan die roll dengan bahan material AISI 1045 panjang $180 \mathrm{~mm}$. Untuk clamping menggunakan AISI 1045 dan penahan besi poros berdiameter $6 \mathrm{~mm}$.

Cara kerja Mesin Bending Rotary ini adalah sebagai berikut: bahan baku stainless round bar untuk pembuatan hanger gantungan ayam potong berdiameter $6 \mathrm{~mm}$ setelah melalui proses cutting dengan panjang tertentu dimasukkan ke roller dan dikunci dengan menggunakan pin pengunci. Setelah itu hidupkan mesin dengan cara menekan switch pada posisi 'on' sehingga roller dan clamping yang telah mengunci material tersebut akan berputar sampai sudut yang di kehendaki. Selanjutnya lepas pin pengunci dan ambil material yang telah ter-bending dan periksa sudut yang terbentuk. 


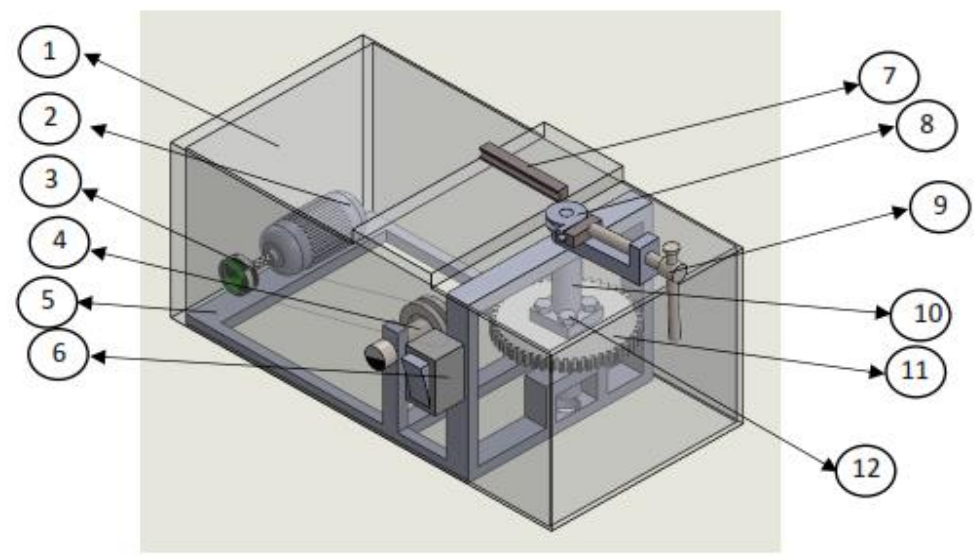

\section{Keterangan :}

1. Body Luar Mesin

2. Motor Listrik $1 / 2 \mathrm{HP}$

7. Clamping

3. Pulley Motor Listrik

8. Roller

4. Counter Shaft

5. Rangka

9. Pin Pengunci

6. Switch

10. Poros Transmisi

11. Gear

12. Mur dan Baut

Gambar 4. Konstruksi mesin bending

\subsection{Proses Pembuatan Mesin Bending Rotary}

Proses Pembuatan komponen dan perakitan dilakukan setelah melakukan redesain mesin bending rotary selesai. Pada dasarnya desain yang digunakan adalah desain simultan yang dilakukan bebarengan dengan desain manufaktur seperti yang terlihat pada Gambar 5. Kualitas proses pengerolan yang diperoleh tersebut ditentukan oleh tahapan proses pengerolan yang efektif berdasarkan produk yang akan dihasilkan melalui proses pengerolan[10].

Dalam pembuatan komponen dan perakitan mesin dibutuhkan alat penunjang yaitu mekanik tool set, mata gerinda, rol meter, dan kuas. Pembuatan komponen dimulai dari body mesin dari material besi hollow 40mm x 40mm x $2 \mathrm{~mm}$ dan juga plat galvanis dengan tebal $2 \mathrm{~mm}$ yang dipotong menggunakan mesin gerinda. Selanjutnya, pembuatan die roll dari AISI 1045 tebal $40 \mathrm{~mm}$ dipotong dengan mesin gerinda sesuai dengan desain, tahap berikutnya adalah disambung dengan mesin las. Roller dibuat dari AISI 1045 yang dibubut menggunakan mesin bubut sampai diameter 15mm dan tebal $20 \mathrm{~mm}$. Die roll dibuat dari bahan AISI 1045 yang dibubut sampai diameter $15 \mathrm{~mm}$ dan panjang 180mm. Setelah itu, buat dudukan untuk transmission gear dengan tebal 20mm yang terbuat dari plat galvani lalu diberi lubang untuk mur dan baut menggunakan mesin bor.

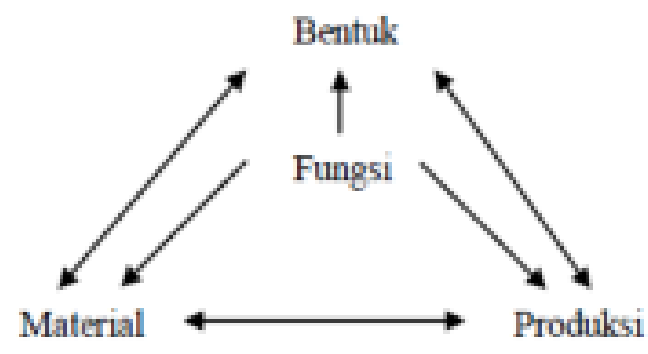

Produksi $=$ manufaktur + merakit

Gambar 5. Elemen dasar desain simultan 
Setelah pembuatan dan pengadaan komponen selesai, langkah selanjutnya yaitu perakitan mesin. Pertama, assembly semua komponen yang telah dibuat sesuai dengan kontruksi yang telah dirancang. Kemudian, semua komponen diikat pada kerangka yang telah diberi lubang dengan mesin bor menggunakan mur dan baut M8. Setelah itu, pasang pulley B1 3 Inchi dan pulley B1 8 Inchi pada sistem transmisi mesin, lalu hubungkan dengan V-Belt B-27. Selanjutnya, pasang pasak 7 X $7 \mathrm{~mm}$ untuk mengunci pulley pada poros. Setelah itu pasang stopper dan speed control pada mesin. Setelah semua perakitan selesai, permukaan mesin didempul dan diamplas sampai halus. Pada proses finishing mesin dicat yang dicampur dengan thinner daimaru untuk menambah nilai estetika dan mencegah korosi. Terakhir, cat dilapisi dengan clear agar lebih tahan lama.

\subsection{Pengujian Fungsi Alat.}

Pengujian fungsi alat dilakukan setelah proses pembuatan mesin bending rotary selesai tujuannya adalah untuk memastikan mesin dapat berfungsi dengan baik. Pengujian dilakukan dengan cara membending 1 (satu) set komponen hanger gantungan ayam potong yang terdiri dari 5 (lima) batang raound bar dengan panjang berbeda. Adapun hasil pengujian dapat ditunjukkan pada Tabel 1 berikut ini.

Tabel 1. Hasil Pengujian

\begin{tabular}{cccc}
\hline Sampel uji & $\begin{array}{c}\text { Waktu } \\
\text { (detik) }\end{array}$ & $\begin{array}{c}\text { Kualitas } \\
\text { G/NG }\end{array}$ & Keterangan \\
\hline Hanger 1 & 124 & G & \\
Hanger 2 & 122 & G & \\
Hanger 3 & 121 & G & \\
Hanger 4 & 119 & NG & \\
Hanger 5 & 120 & G & \\
Hanger 6 & 120 & G & \\
Hanger 7 & 119 & G & \\
Hanger 8 & 120 & G & \\
Hanger 9 & 120 & G & Satu batang sudutnya kurang $3^{\circ}$ \\
Hanger 10 & 118 & NG & \\
\hline
\end{tabular}

Sumber: Data Primer yang diolah, Tahun 2021

Keterangan:

- G : Good (sudut bending dari lima komponen batang round bar sudah sesuai)

- NG: Not Good (sudut bending dari lima komponen batang round bar ada yang tidak sesuai )

3.4. Analisis Hasil Pengujian.

Dari data hasil pengujian seperti dalam tabel 1, dapat dilakukan analisis sebagai berikut:

- Dengan menggunakan mesin bending rotary proses bending untuk 1set hanger gantungan ayam potong membutuhkan waktu rata-rata 120,3 detik. Sementara dalam membending 10 set hanger terdapat 2 batang NG yang membutuhkan waktu repair 120 detik. Waktu repair per hanger rata-rata membutuhkan waktu 12 detik. Sehingga total waktu untuk proses banding satu set hanger dengan menggunakan mesin rotary penggerak motor listrik adalah 243,3 detik.

- Dengan menggunakan mesin bending konvensional proses bending untuk komponen 1set hanger gantungan ayam potong membutuhkan waktu rata-rata 300 detik. Sementara waktu repair per hanger rata-rata 
Ampala Khoryanton dkk /Jurnal Rekayasa Mesin

p-ISSN: 1411-6863, e-ISSN: 2540-7678

Vol.16|No.3|417-424|Desember|2021

membutuhkan waktu 600 detik. Total waktu untuk proses banding satu set hanger dengan menggunakan mesin konvensional adalah 900 detik.

- Dengan dengan menggunakan mesin rotary penggerak motor listrik dapat mempercepat proses bending 656,7 detik dibandingkan dengan menggunakan mesin bending manual sebelumnya.

\section{Kesimpulan}

Berdasarkan uraian dari pembahasan mesin bending rotary baja beton maka dapat diambil kesimpulan sebagai berikut:

1) Mesin bending rotary untuk pembuatan hanger gantungan ayam potong memiliki spesifikasi dimensi ukuran $600 \mathrm{~mm}$ x $600 \mathrm{~mm}$ x $1200 \mathrm{~mm}$, sumber tenaga penggerak motor listrik 0,5 HP. Kerangka mesin terbuat dari bending rotary siku $40 \mathrm{~mm} \times 40 \mathrm{~mm} \times 2 \mathrm{~mm}$ dan besi hollow $40 \mathrm{~mm} \times 40 \mathrm{~mm} \times 2 \mathrm{~mm}$ sebagai penopang komponen bending rotary agar mesin menjadi kokoh saat digunakan.

2) Proses bending menggunakan mesin bending rotary ini jauh lebih efisien dibanding melakukan bending manual sebelumnya. Dengan dengan menggunakan mesin rotary penggerak motor listrik dapat mempercepat proses bending 656,7 detik dibanding proses bending manual.

\section{DaftarPustaka}

[1] Maimun, M., et al. (2018). Pembuatan Mesin Bending Pipa. Jurnal Mesin Sains Terapan. Vol 2 (2): 105-109.

[2] Dullah, M. J., et al. (2020). Desain dan Analisis Alat Bending V Sistem Hidro Pneumatik. Jurnal Teknik Mesin Sinergi. Vol 17 (2): 168-178.

[3] Siboro, B. A. H., Afma, V. M., \& Pratama, A. (2018). Perancangan Mesin Bending untuk Menurunkan Reject Mechanical Packing Kapasitor. j. sist. manaj. ind, 2(1), 9-16.

[4] Debora, F., Prasetyo, M. A., \& Rosma, R. (2021). Peningkatan Produktivitas Part X Pada Mesin Bending LR. Jurnal Inkofar, 5(1).

[5] Alamsyah, S., \& Saleh, A. (2019). Perancangan Sistem Kontrol PLC Pada Mesin Bending Rol Pipa. Jurnal TEDC, 13(3), 228-232.

[6] Nurcahyo, Y. E., \& Ellianto, M. S. D. (2018). Rancang Bangun Mesin Roll Bending Portable. Teknika: Engineering and Sains Journal, 2(2), 109-114

[7] Marcharla, Ashok., \& Raghavaraju, Thirupathi. (2017). Design and Analysis of Rotary Draw Tube Bending Machine International Journal of Innovative Research in Technology. Vol 4 Issue 5. Syafrizal., \& S, Adolf,

[8] Christopher, H., Steinheimer, R., \& Bernd, E. (2018). Rotary Draw Bending Using Tools with Reduced Geometries. International Conference on Metal Forming, Metal Forming.

[9] Syafrizal, S. (2017). Pemilihan Daya Motor Sebagai Sumber Penggerak Dengan Menggunakan Transmisi Pulley Dan Belt Tipe-V. Jurnal Elektra, 2(1), 8-12.

[10] Zufar, S., R. (2017). Analisis Springback Tube Stainless Steal 304L Berpenampang Lingkaran dan Elips Pada Proses Rotary Draw Bending.

[11] Suryanto, H., Aminnudin, A., Aminnudin, S., Pradana, Y. R., Dharmabintara, R. A., Muhajir, M., \& Muslim, F. (2018). Penerapan Mesin Rol Pipa Hidrolis Pada Bengkel Modifikasi Konstruksi Motor Trail. Jurnal KARINOV, 1(3).

[12] Rusnandi, R., et al. (2020). Perancangan Mesin Bending Untuk Pipa Berdiameter Satu Inch Menggunakan Metode Roll Bending. TEKNIKA: Jurnal Teknik. Vol 7 (1) : 49-56. 
[13] Nurcahyo, Y. E. and M. S. D. Ellianto (2018). Rancang Bangun Mesin Roll Bending Portable. Teknika: Engineering and Sains Journal. Vol 2 (2): 109-114.

[14] Sufiyanto, S. (2020). Analisis Proses Pengerolan Pipa dengan Roll Bending. TRANSMISI. Vol 7 (1) : 639648.

[15] Asih. (2017). Pemilihan Daya Motor Sebagai Sumber Penggerak Dengan Menggunakan Transmisi Pulley dan VBelt. Vol.2, No.1. Politeknik Enjinering Indorama. 